\title{
Jurisdicción nacional y control de convencionalidad a propósito del diálogo judicial y de la tutela multinivel de derechos DE LUIS JIMENA QUESADA, ESPAÑA, ARANZADI, 2013
}

Fátima ROSTRO HERNÁNDEZ

El profesor valenciano Luis Jimena, ${ }^{2}$ realiza en esta ocasión, y luego de varias producciones científicas relevantes para los estudios jurídicos, ${ }^{3}$ una obra relativa a las fuentes del Derecho, concretamente sobre las normas producidas por instituciones europeas y las emanadas por los poderes estatales internos con especial referencia al caso español, así como los pronunciamientos que al respecto emiten los organismos jurisdiccionales de dicho país.

En este tenor, comentaremos en breves líneas, algunos de los temas referidos por el profesor, tal y como se presentan a continuación. El autor refiere, que el sistema de fuentes del Derecho, ha adquirido un alto nivel de complejidad, contribuyendo con ello, a la progresiva aceptación de la tesis de integración de los tratados válidamente suscritos por un Estado de conformidad con su ordenamiento jurídico interno, máxime cuando se trata de la Constitución, como sucede en el caso español ${ }^{4}$. A dicha complejidad le suma, la creación de medios de control, como métodos de respuesta ante los posibles conflictos de colisión entre las normas convencionales e internas como el "control de convencionalidad".

Ante este panorama Jimena señala, que la integración normativa entre el Derecho internacional de derechos humanos y el ámbito constitucional, conlleva no solo a la ampliación

\footnotetext{
${ }^{1}$ Maestra en Derecho Constitucional y Administrativo por la Universidad DeLa Salle Bajío, y Doctorante en Derecho por el Programa Interinstitucional de las Universidades de la Región Centro Occidente de ANUIES. Profesora de la Maestría en Ciencias Jurídico Penales de la División de Derecho, Política y Gobierno de la Universidad de Guanajuato, e integrante y cofundadora de la Red estatal de profesoras y profesores en Derechos Humanos, Guanajuato.

2 Luís Jimena Quesada es Catedrático de Derecho constitucional en la Universitat de València, en donde se licenció y se doctoró con premio extraordinario, siendo el primer doctor europeo en Derecho de dicha Universidad. Es profesor y miembro del Instituto Internacional de Derechos Humanos, y actualmente miembro del Comité Europeo de Derechos Sociales del Consejo de Europa (mandato de seis años, del 1 de enero de 2009 al 31 de diciembre de 2014).

3 Cuenta con más de un centenar de publicaciones, siendo autor en concreto de once libros y pudiendo mencionarse como más recientes en el ámbito de los derechos humanos: Escritos sobre Derecho Europeo de los Derechos Sociales (Valencia, Tirant lo Blanch, 2004), European Constitution and Competition Policy (Roma, Philos Edizioni, 2005), Sistema Europeo de Derechos Fundamentales (Madrid, Colex, 2006), La Jurisprudencia del Comité Europeo de Derechos Sociales (Valencia, Tirant lo Blanch, 2007), y Dignidad humana y justicia universal en España, (Pamplona, Thomson/Aranzadi, 2008).

${ }^{4}$ Cabe recordar que cada vez son más los países que amplían su sistema de fuentes del Derecho, tal como se observa con la incorporación constitucional de tratados de Derecho internacional sobre derechos humanos; experiencia que se ve materializada en países como México, Argentina, Guatemala, España entre otros. Y que dicha afirmación constitucional, conlleva además al reconocimiento implícito de la jurisprudencia internacional, emitida por los órganos jurisdiccionales, inmersos en los sistemas regionales de protección de derechos humanos; situación que es atendida vía interpretación nacional por los Tribunales constitucionales, en algunos casos como criterio orientador y en otros como criterio vinculante, para la resolución de casos en concreto.
} 
de las fuentes del Derecho nacional, sino además dota a las y los jueces de mayores herramientas jurídicas para la interpretación y aplicación de justicia; así como al fortalecimiento del sistema de protección derechos humanos.

No obstante, reconoce una serie de tensiones que se dan en la aplicación jurisdiccional nacional del derecho internacional sobre derechos humanos, y las que emanan al ejercer el examen de compatibilidad entre normas convencionales y nacionales en el ámbito interno. En este sentido, se hace una serie de cuestionamientos, como los siguientes: ¿es posible el ejercicio del control convencional en países donde se reconocen a los tratados internacionales de derechos humanos?, y si fuese posible, se pregunta a su vez: ¿a qué se debe que unos jueces ejercen dicho control y otros no?, y añade: ¿serán los principios procedimentales o la falta de una posición adecuadamente fundamentada en los contenidos que constituyen el objeto de dicho control, las dificultades para su real aplicación?.

Para responder a estas y otras preguntas, el autor desarrolla en la obra argumentos teóricos y prácticos, que le permiten asumir la postura no solo de su factibilidad, sino además de la exigencia de ejercer el control convencional por la jurisdicción ordinaria, aunque reconoce que dicha figura sea apenas desarrollada por la doctrina científica española, sobre todo en el terreno del Derecho constitucional, el Derecho internacional y el Derecho procesal.

En este tenor se señala, que para desarrollo exitoso del control de convencionalidad será necesario, entre otros aspectos, fortalecer el diálogo entre las jurisdicciones nacionales, y entre los órganos nacionales e internacionales de garantía; comprender que dicho control ya no puede ser visto como una competencia de exclusividad por los tribunales internacionales; perfeccionar no solamente la formación de la judicatura, sino de aquellos que ejercen la abogacía, u otra profesión que impacte en el proceso judicial.

Con todo ello, busca promover y fortalecer una conciencia constitucional en asunción a los compromisos internacionales, en materia de derechos humanos por los Estados parte, quienes voluntariamente amplían su sistema de fuentes del Derecho, para obligarse a ejercer, ya no solamente un control constitucional sino además un control de convencionalidad, redundando finalmente en una eficaz protección de derechos fundamentales.

Así pues, la obra de Jimena, constituye sin duda un extraordinario referente desarrollado en cinco capítulos, sobre el sistema de fuentes del Derecho, el control de convencionalidad y su relación con las jurisdicciones nacionales; así como la tutela multinivel de derechos, todos ellos tópicos de relevancia indiscutible en el debate jurídico actual relativo a la aplicación jurisdiccional de los derechos humanos en México. 